\title{
Climatic and spatial variations of potential rainwater savings for Melbourne (Australia)
}

\begin{abstract}
A daily water balance model is used for the performance analysis and calculation of potential rainwater savings from household rainwater tanks under different scenario for a major Australian city, Melbourne. To investigate the climatic variabilities of rainwater tank outcomes nine representative years (three for each dry, average and wet condition) are selected from historical rainfall data. For the three climatic conditions, a number of rainwater tank outcomes (water savings, townwater augmentation, overflow) are presented in relations to tank volume, roof area, number of people in a house (i.e., water demand). For spatial variability investigation, two distant ( $25 \mathrm{~km}$ apart) localities within Melbourne were selected; one in central Melbourne and the other in North Melbourne. It is demonstrated that significant climatic and spatial variabilities exist in regards to studied rainwater tank outcomes, except for very few conditions having tanks connected with large roofs under low demand scenario. Also, computed variabilities are higher than the expected climatic variabilities computed for an Australian inland city, Canberra. Eventually, an economic analysis is presented showing potential money savings and payback periods for different tank options.
\end{abstract}

Keyword: Rainwater tanks; Climatic conditions; Spatial variability; Payback period; Australia; Climate variation; Rainwater savings; Water balance modelling; Household tanks; Economic analysis; Water savings; Townwater augmentation; Overflow; Tank volume; Roof area; Water demand 